\title{
Dini Tesis Yapılacak En İyi Konumun K-means Kümeleme Yöntemleri ile Tespit Edilmesi
}

\author{
Nuh Mehmet Özmerdivenli ${ }^{1}$, Murat Taşyürek ${ }^{2 *}$, Bahatdin Daşbaş1 ${ }^{3}$ \\ ${ }^{1}$ Kayseri Üniversitesi, Lisansüstü Eğitim Enstitüsü, Hesaplamalı Bilimler ve Mühendislik Ana Bilim Dalı, ORCID (0000-0002-0854-2280) \\ n.mehmetozmerdivenli@gmail.com \\ 2* Kayseri Üniversitesi, Mühendislik Mimarlık ve Tasarım Fakültesi, Bilgisayar Mühendisliği Bölümü, Kayseri, Türkiye, (ORCID: 0000-0001-5623-8577), \\ murattasyurek@kayseri.edu.tr \\ ${ }^{3}$ Kayseri Üniversitesi, Mühendislik Mimarlık ve Tasarım Fakültesi, Mühendislik Temel Bilimler Bölümü, Kayseri, Türkiye, (ORCID: 0000-0001-8201-7495), \\ bdasbasi@kayseri.edu.tr
}

(Uluslararası Araştırma-Geliştirme ve Tasarım Konferansı - 15-18 Aralık 2021)

(DOI: 10.31590/ejosat.1037519)

ATIF/REFERENCE: Özmerdivenli, N. M., Taşyürek, M. \& Daşbaşı, B. (2021). Dini Tesis Yapılacak En İyi Konumun Kümeleme Yöntemleri ile Tespit Edilmesi: Kayseri Örneği. Avrupa Bilim ve Teknoloji Dergisi, (32), 424-430.

\section{$\ddot{O} \mathbf{z}$}

Önemli noktalar, insanlar tarafindan ilgi çekici bulunan ve etkileşim kurulmak istenen konum olarak ifade edilir. Dini tesisler insanlar tarafından sıklıkla kullanılan önemli noktalardan bir tanesidir. Dini tesisler insanlar tarafından sıklıkla kullanıldığından dolayı konumları da etkileşim açısından çok büyük önem arz etmektedir. Son dönemlerde yaşanan pandemi süreci de göz önüne alındığında virüsün yayılma hızını azaltmak için insanların bir araya geldiği dini tesis noktalarında yoğunluğu azaltmak veya dengelemek gerekmektedir. Yoğunluk tabanlı analizleri için en yaygın kullanılan ve en baist algoritma olarak ifade edilen k-means algoritması kullanılmaktadır. Tüm bu nedenlerden dolayı yeni yapılacak POI noktalarının yoğunluklara göre dağıtılması çok büyük önem arz etmektedir. Bu çalışmada, dini tesis yapılacak noktaların sadece mesafeye göre değil aynı zamanda nüfus yoğunluğunu dikkate alması için çok boyutlu k-means tabanlı yeni bir yaklaşım önerilmiştir. Bu çalışmada önerilen modelde Kayseri Büyükşehir Belediyesi ve Melikgazi Belediyesine ait mekânsal bina ve dini tesis verileri kullanılmıştır. Önerilen çok boyutlu k-means modelinde, nüfus yoğunluğunu dengelemek için bina verilerinde buluan bağımsız bölüm sayısı boyut olarak dikkate alınmıştır. Önerilen çok boyutlu k-means modelinin performansı gerçek veriler üzerinde klasik iki boyutlu k-means yönteminin performansı ile karşılaştırılmıştır. Deneysel sonuçlar, önerilen çok boyutlu k-means yaklaşımının iki boyutlu k-means yaklaşımına göre nüfüs yoğunluğu açısından daha başarılı sonuçlar ürettiğini göstermiştir.

Anahtar Kelimeler: Çok boyutlu kümeleme, K-means, Mekansal veri.

\section{Determining the Best Location for a Religious Build by K-means Clustering Methods}

\begin{abstract}
Point of Interest is expressed as locations that people find interesting and want to interact with. Religious facilities are one of the important points frequently used by people. Since religious facilities are frequently used by people, their location is also of great importance in terms of interaction. Considering the recent pandemic process, it is necessary to reduce or balance the density at religious facility points where people come together in order to reduce the spread of the virus. The k-means algorithm, which is the most widely used and expressed as the simplest algorithm, is used for density-based analysis. For all these reasons, it is very important to distribute the new POI points according to their densities. In this study, a new multidimensional k-means based approach is proposed to consider the distance and the population density of the points where religious establishments will be built. In this study, spatial building and religious facility data belonging to Kayseri Metropolitan Municipality and Meligkazi Municipality were used in the proposed model. In the proposed multidimensional k-means model, the number of independent sections in the building data is taken into account to balance the population density. The performance of the proposed multidimensional k-means model is compared with the performance of the classical two-dimensional k-means method on real data. Experimental results showed that the proposed multidimensional k-means approach produced more successful results in terms of population density than the two-dimensional k-means approach.
\end{abstract}

Keywords: Multidimensional clustering, K-means, Spatial data.

\footnotetext{
*Sorumlu Yazar: murattasyurek@kayseri.edu.tr
} 


\section{Giriş}

İlgi çeken noktalar (Point of Interest -POI), insanlar tarafından ilgi çekici bulunan ve etkileşim kurulmak istenen konum olarak ifade edilmektedir (Wang ve ark., 2018). Dini tesis, okul, hastane ve eczane gibi günlük hayatta yaygın olarak kullanılan konumlar POI olarak tanımlanmaktadır (Krause ve ark., 2019). POI verileri coğrafi bilgi sistemlerinde en yaygın kullanılan mekânsal verilerden bir tanesidir (Deng ve ark., 2021; Taşyürek ve ark., 2021). POI verileri konum tabanlı uygulamalar ve analizler için temel veri kaynağı olduğundan dolayı önem arz etmektedir (Yu ve ark., 2020; Taşyürek, 2021). Ayrıca, POI noktaları insanlar tarafından sıklıkla kullanıldığından dolayı konumları da etkileşim açısından çok büyük önem arz etmektedir. Diğer taraftan, nüfus artış hızının da etkisiyle kentlerde yaşayan nüfus sayısı gün geçtikçe artış eğilimindedir. Tüm bu gerekçelere ek olarak son dönemlerde yaşanan pandemi süreci de göz önüne alındığında virüsün yayılma hızını azaltmak için insanların bir araya gelebilecekleri alanlarda yoğunluğu azaltmak gerekmektedir. Tüm bu nedenlerden dolayı yeni yapılacak POI noktalarının yoğunluklara göre dağıtılması çok büyük önem arz etmektedir.

POI noktaları mekânsal veriler olduğundan dolayı yoğunluğun önem arz ettiği analizler için literaratürde sıklıkla yoğunluk tabanlı kümeleme yöntemleri kullanılmaktadır (Ke ve ark., 2018; Long ve ark., 2021). Kümeleme, bir veri kümesini gruplara ayırma olarak ifade edilmektedir (Askarovich, 2021). Diğer bir ifade ile kümleme, farklı küme içerisindeki veri noktaları arasındaki benzerlik çok farklı, aynı küme verilerin benzerlik oranının yüksek olması nedeniyle verilerin alt veri gruplarına ayrılması olarak tanımlanır (Caron ve ark., 2020). Yoğunluk tabanlı kümeleme ise veri alanındaki bir kümenin, bu tür diğer kümelerden düşük noktalı bitişik bölgelerle ayrılan, yüksek nokta yoğunluklu bitişik bir bölge olduğu fikrine dayanarak, verilerdeki ayırt edici grupları/kümeleri tanımlayan denetimsiz öğrenme yöntemi olarak tanımlanmaktadır. K-means kümeleme yöntemi en basit ve en popüler kümeleme yöntemi olarak kabul görmektedir (Likas ve ark., 2003; Na ve ark., 2010). $\mathrm{K}$-means kümeleme yöntemi $\mathrm{n}$ adet veri içeren veri grubundan $\mathrm{k}$ adet kümeye oluşturan, benzer niteliklere sahip verileri aynı gruba dahil eden ve adını kümedeki değerlerin ortalamasını hesaplamasından alan kümeleme yöntemidir (Kodinariya ve ark., 2013). Brimicombe (2007), trafik kaza yoğunlukların küme oluşturulmasında k-means algoritmasından yararlanmıştır. Anderson (2009), trafik kazalarının yoğun olduğu noktaların belirlenmesi için coğrafi bilgi sistemlerini ve k-means algoritmasını kullanmıştır. Kuswandi vd. (2018) proje tabanlı öğrenme modeli uygulamasına ilişkin öğrenci algılarının k-means algoritması ile kümelenmesi üzerine bir çalışma gerçekleştirmiştir. El Khediri vd. (2020) kablosuz sensör ağları için k-means kümeleme yöntemini kullanılarak iyileştirilmiş düğüm yerelleştirmesi üzerine bir çalışma yapmıştır.

Bu çalışmada, ibadet etmek için kullanınan ve POI öğelerinin en önemlerinden biri olan dini tesis (Hashim ve ark., 2011) konumları k-means tabanlı yeni bir yaklaşım önerilmiştir. Bu çalışmada önerilen yaklaşımda Melikgazi Belediyene ait gerçek bina ve dini tesis verileri kullanılmıştır.

\section{Materyal ve Metot}

\section{1. İki Boyutlu K-means}

$\mathrm{K}$-means kümeleme yöntemi $\mathrm{n}$ adet veri içeren veri grubundan $\mathrm{k}$ adet kümeye oluşturan, benzer niteliklere sahip verileri aynı gruba dahil eden kümeleme yöntemidir (Kodinariya ve ark., 2013). K-means algoritmasında, veri setinde etiketleri belli olmayan verilerin hangi sınıfa dahil olacağı belirlenerek küme içi benzerlik maximum kümeler arası benzerlik ise minimum olacak şekilde kümeleme yapılması amaçlanmaktadır. K-means yönteminde küme sayısı araştırmacının önbilgisine ve tecrübesine bağlı olarak belirlenmektedir (Han ve ark., 2009). İki boyutlu k-means yöntemi kullanılarak yapılan çalışmalarda veri setinde belirlenen iki öznitelik değerini kullanarak başlangıçta rastgele seçilen küme merkezlerine olan uzaklık her bir veri için hesaplanmakta ve etiketleri belirlenen verilere göre küme merkezleri her bir iterasyon için güncellenmektedir. K-means algoritması küme merkezleri değişmeyene kadar her bir verininin küme merkezine olan uzaklığını hesaplayıp veri kümesini güncellemektedir (Hamerly ve ark., 2003). K-means yöntemiyle kümelemede, temel olarak benzer özellik gösteren veriler kendi aralarında gruplara ayrılmaktadır (Çolak ve ark., 2016). Yaygın olarak kullanılan denetimsiz öğrenme metodlarından biri olan Kmeans kümeleme yöntemi her verinin sadece bir kümeye ait olmasına olanak sağlayan keskin bir kümeleme algoritması olarak da ifade edilmektedir (Sariman, 2011).

K-means kümeleme algoritmasının işlem adımları aşağıdaki gibi sıralanmaktadır (Han ve ark., 2009):

k: küme sayısı

$\mathrm{D}=\left\{\mathrm{t}_{1}, \mathrm{t}_{2}, \ldots, \mathrm{t}_{\mathrm{n}}\right\}: \mathrm{n}$ sayıda öğresi olan bir veri grubunu temsil etmek üzere;

1. D veri grubundan başlangıçta belirtilen kümeler için başlangıç ortalama değerleri $\mathrm{m}_{1}, \mathrm{~m}_{2}, \ldots, \mathrm{m}_{\mathrm{k}}$ olarak tanımlanır.

2. Her bir $t_{i}$ öğesi en yakın olduğu $m_{i}$ 'nin kümesine atanır.

3. Kümelere ait ortalama $m_{1}, m_{2}, \ldots, m_{k}$ değerleri yeniden hesaplanır.

4. Ortalama $\mathrm{m}$ değerlerinde herhangi bir değişiklik yok ise algoritma görevini tamamladığı için durdurulur.

5. Değişiklik varsa ilk adımdan (1. adım) itibaren tekrar edilir.

\section{2. Çok Boyutlu K-means}

Çok boyutlu k-means algoritması klasik k-means algoritmasının farklı boyutlarıda dikkate alması için geliştirien algoritmasıdır (Zeng ve ark., 2007). Çok boyutlu k-means yöntemi ile iki boyutlu k-means yönteminden farklı olarak veri setinde istenildiği kadar öznitelik değeri kullanılarak kümeleme yapılabilmektedir. Veri setinde kümelemeyi etkileyecek her bir öznitelik değeri sisteme kazandırılarak kümeleme doğruluğunun artırılması hedeflenmektedir. Çok boyutlu k-means yöntemi kullanılarak, veri gruplarında bulunan mekânsal verilerin birden fazla özelliği irdelenerek ve bu özelliklerin birbirleriyle olan ilişkileri ortaya çıkarılarak farklı mekânsal verilerin benzer yönlerini gösteren özellikleri ortaya çıkarılabilir ve bu sayede risk analizi, planlama ve bunlara benzer uygulamar için önemli derecede katkı sağlayan mekânsal analizler yapılmaktadır (Selvi ve ark., 2017). 


\section{Problem ve Çözümler}

Problem, dini tesislerde oluşan yoğunluk ve pandemi etkisiyle ortaya çıkmıştır. İlk olarak uygulamada, klasik kümele yöntemi olan iki boyutlu k-means algoritması kullanılarak dini tesis yapılacak en uygun konum tespit edilmeye çalışılmıştır. Ancak, analiz aşamasında iki boyutlu k-means algoritmasının sadece mekansal mesafeleri dikkate aldığından dolayı asıl problem olan nüfus yoğunluğuna bir çözüm üretemediği tespit edilmiştir. Bu sorunun üstesinden gelmek, mekansal mesafenin yanısıra bina nüfüs yoğunluğunu da dikkate almak için çok boyutlu k-means kümeleme yöntemi ile en uygun konum tespit edilmeye çalışılmıştır.

\section{1. İki Boyutlu K-means Algoritması ile Çözüm}

K-means algoritasını diğer kümele algoritmalarından ayıran en önemli özelliklerden biri de veri kümesinde bulunan öğenin illaki bir kümeye dahil olmasıdır. Diğer bir ifade ile kümele işlemi sonucunda hiçbir boşta olan öğe (noisy point) kalmamaktadır. Problem, bina verileri için en uygun dini tesis konumu bulunacağından dolayı ve her binanın bir kümeye dahil olması gerektiğinden dolayı k-means algoritması problemin çözümü için uygulanabilir. Ayrıca, k-means algoritmasının zorluklarından biri de başlangıçta küme sayısının belirtilmesi gerekmektedir. Dini tesis yapılacak konum sayısı diğer bir ifade ile dini tesis sayısı önceden bilindiğinden dolayı küme sayısı açısından da k-means yöntem olmasına rağmen bina nufüs yoğunluğunu dikkate almadığından dolayı asıl probleme çözüm üretememektedir. $\mathrm{Bu}$ nedenle, sorunun üstesinden gelmek, mekansal mesafenin yanısıra bina nüfus yoğunluğunu da dikkate almak için çok boyutlu k-means kümeleme yöntemi ile en uygun konum tespit edilmeye çalışılmıştır. İki boyutlu k-means algoritması ile oluşturulan çözümden farklı olarak çok boyutlu k-means algoritması ile önerilen çözümde mesafe olarak çok boyutlu Öklid mesafesi (Kozinska ve ark., 1997) kullanılmıştır. Küme öğeleri arasındaki mesafe için boyut olarak mekânsal mesafe ve bina bağımsız bölüm sayısı (bina içerisinde bulunan daire sayısı) kullanılması planlanmıştır.

\section{Araştırma Sonuçları ve Tartışma}

Bu çalışmada Melikgazi Belediyesi ve Kayseri Büyükșehir Belediyesi'nden alınan Melikgazi ilçesinin Alparslan mahallesine ait bina ve dini tesis verileri kullanılmışır. Tablo 1'de bu çalışmada kapsamında kullanılan verilerin özet bilgisi gösterilmiştir.

Şekil 1'de bu Melikgazi ilçe sınırları içerisinde bulunan Alpaslan mahallesinin harita üzerindeki konumu sunulmuş olup diktörgen ile belirtilen bölge Alpaslan mahallesinin sınırlarını ifade etmektedir.

\section{Tablo 1. Mekânsal Veri Öznitelik Bilgisi}

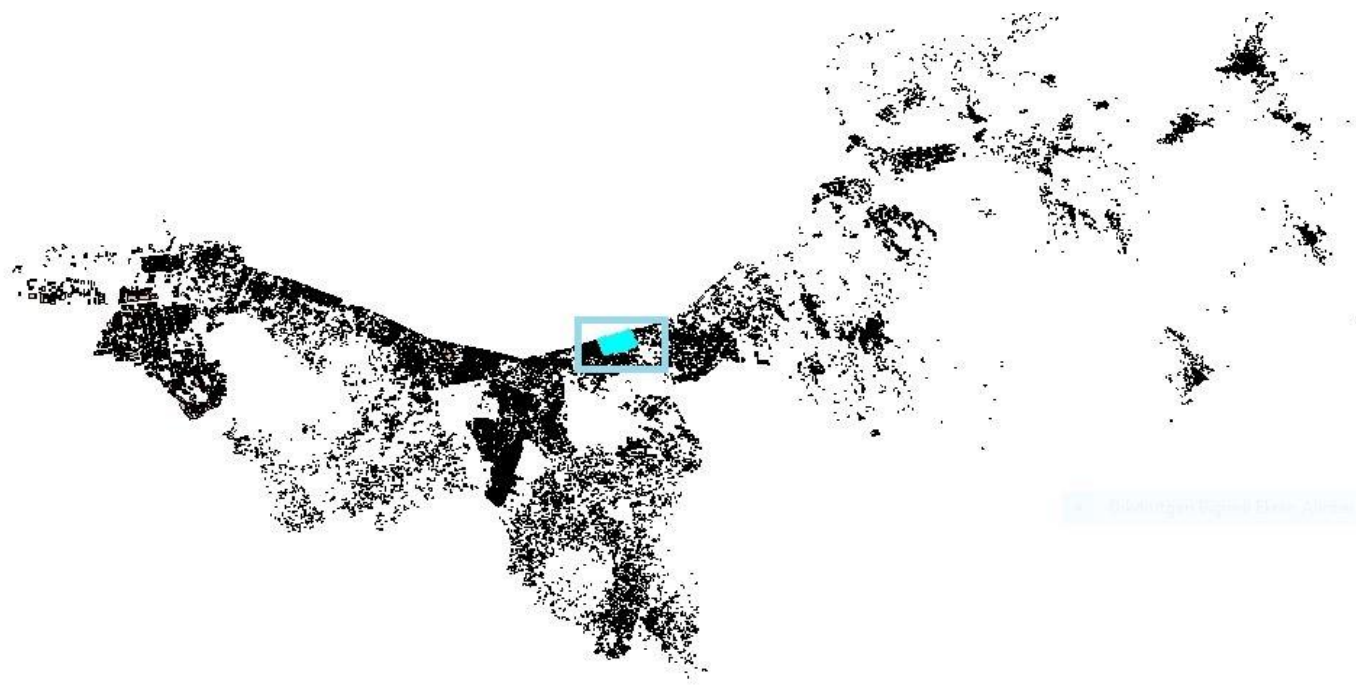

Şekil 1 Melikgazi Sinır ve Alparslan Mahallesi

algoritması problemin çözümü için uygulanabilir. K-means algoritmasında küme başlangıç noktası kümeleme işleminin doğruluğu etkilediğinden dolayı çok büyük önem arz etmektedir (Shouman ve ark., 2012). İki boyutlu k-means algoritmasında küme başlangıç merkez noktaları için mevcut yapılmış olan dini tesislerin konumları seçilmesi planlanmıştır. İki boyutlu k-means yönteminde öğeler arasındaki mesafe için literartürde yaygın olarak kullanılan iki boutlu Öklid mesafesinin (Danielsson, 1980) kullanılması planlanmıştır.

\section{2. Çok Boyutlu K-means Algoritması ile Çözüm}

İki boyutlu k-means algoritasını boşta kalmayan öğe (noisy point), küme sayısı ve başlangıç küme merkezi açısından en uygun dini tesis yapılacak konumun tespit edilmesi için uygun bir

\begin{tabular}{l|l|l}
\hline $\begin{array}{l}\text { Öznitelik } \\
\text { Adı }\end{array}$ & Veri Tipi & Kullanım Amacı \\
\hline Ilçe & Rakam & $\begin{array}{l}\text { Bina verisinin hangi ilçede } \\
\text { olduğunu gösteren veritabanı } \\
\text { sütunu }\end{array}$ \\
\hline Mahalle & Rakam & $\begin{array}{l}\text { Bina verisinin hangi mahallede } \\
\text { olduğunu gösteren veritabanı } \\
\text { sütunu }\end{array}$ \\
\hline Bina Adı & Metin & $\begin{array}{l}\text { Binanın adını gösteren veritabanı } \\
\text { sütunu }\end{array}$ \\
\hline Kat Adedi & Ralam & $\begin{array}{l}\text { Bir binada toplam kaç kat } \\
\text { bulunduğunu gösteren alan }\end{array}$ \\
\hline
\end{tabular}




\begin{tabular}{l|l|l}
\hline Yapı Türü & Rakam & $\begin{array}{l}\text { Binanın yapı, okul, dini tesis, } \\
\text { kamu kurumu vb. hangi tür } \\
\text { olduğunu gösteren alan }\end{array}$ \\
\hline $\begin{array}{l}\text { Bă̆ımsız } \\
\text { Bölüm } \\
\text { Sayısı }\end{array}$ & Rakam & $\begin{array}{l}\text { Bir binada bulunan toplam } \\
\text { bağımsız bölüm sayısını gösteren } \\
\text { alan }\end{array}$ \\
\hline Konum & Poligon & $\begin{array}{l}\text { Binanın mekânsal olarak konumu } \\
\text { gösteren veritabanı alanı }\end{array}$ \\
\hline
\end{tabular}

$\mathrm{Bu}$ çalışmada yapılan deneyler Intel i7 $117002.5 \mathrm{GHz}(8$ Core), 32 GB Ram, 4 GB QUADRO ekran kart1, 2 TB Satadisk özelliklerine sahip ve Windows 10 Pro işletim kurulu olan masaüstü bilgisayar üzerinde gerçekleş̧irilmiştir.

Bu çalışma kapsamında;

- Veri ön işlemede oracle Express edition 11g sürümü

- Verileri tematik olarak göstermek için ücretsiz CBS yazılımı olan QGIS 3.22 sürümü

\subsection{Deneysel Değerlendirmeler}

Deneysel değerlendirmeler iki boyutlu k-means algoritması ve çok boyutlu k-means algoritması ile dini tesis yapılacak konumların tespit edilmesi amaçlanmıştır. Mevcut veri kümesinde üç adet dini tesis bulunmaktadır. Pandeminin etkisini azaltmak ve nüfüs yoğunluğunu dengelemek için ihtiyaç duyulan dördüncü dini tesisin konumunu tespit etmek amaçlanmıştır. Şekil 2'de sunulan dini tesisler üç adet küme merkezi olarak belirlenmiş ve dördüncü küme merkezi ise her iki yöntemde de değerlendirmenin eşit olması için aynı nokta seçilmiştir. Yöntemlerin başarım performansını değerlendirmek için küme içerisinde bulunan toplam bağımsız bölüm sayısı dikkate alınmıştır.

Şekil 3'te iki boyutlu k-means yönteminin oluşturduğu kümeler, Şekil 4'te çok boyutlu k-means yönteminin oluşturduğu kümeler sunulmuştur. Şekil 3 ve Şekil 4'te nokta üzerinde bulunan $\mathrm{X}$ işareti mevcut dini tesisin konumunu ifade etmektedir.

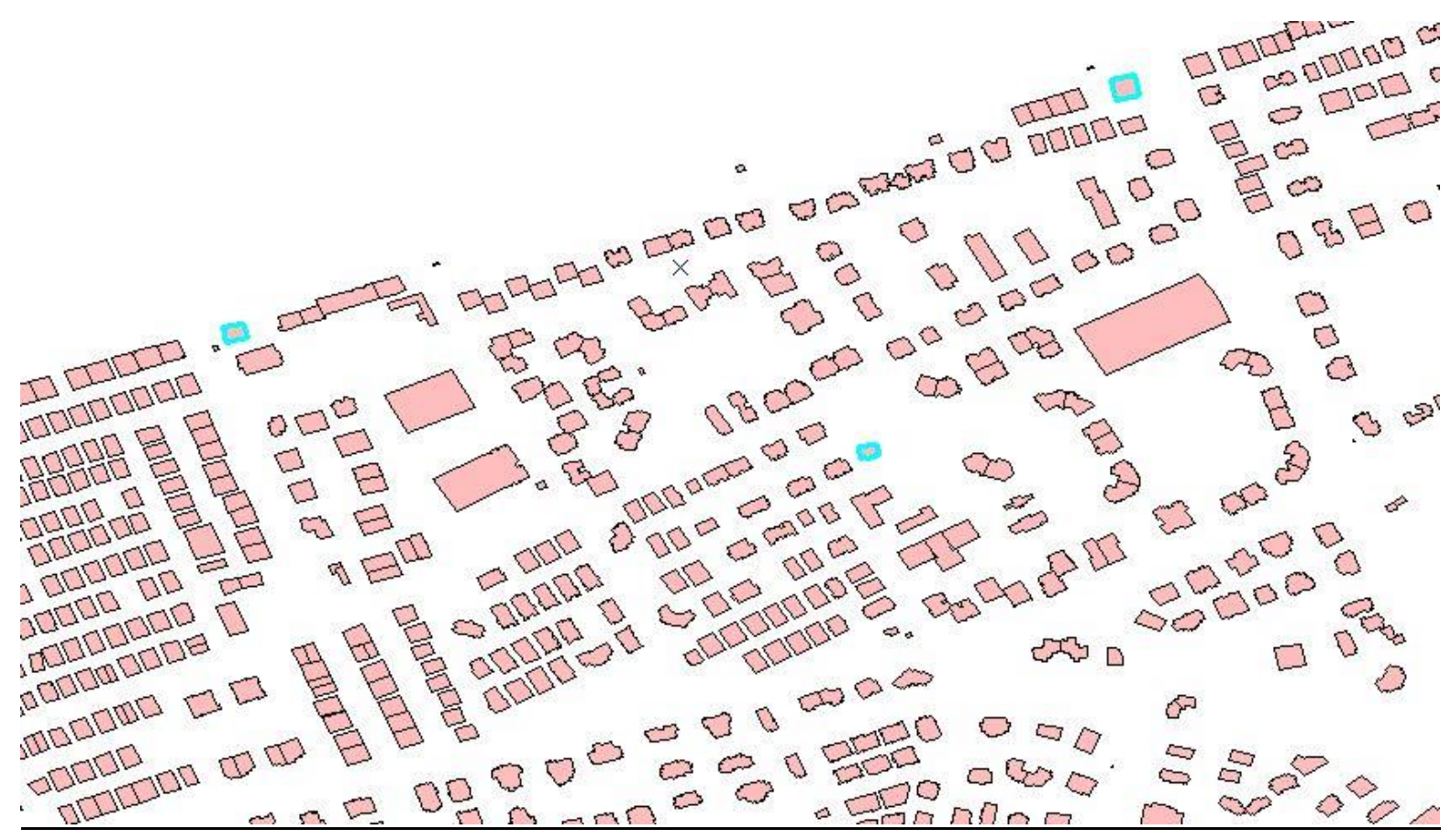

Şekil 2 Alpaslan Mahallesi Dini Tesis Konumları

- K-means kümeleme algoritasmı için Python 3.7 sürümü kullanlmıştır.

Bina verileri poligon tipinde geometrik verilerdir ve içerisinde birden fazla nokta verisi içermektedir. Mekansal mesafe hesabında ise iki nokta arasındaki Öklid mesafesi kullanılmaktadır. Veri ön işleme kısmında bina verilerin nokta formatında olan ağırlı merkezi oracle SDO_GEOM.SDO_CENTROID fonksiyonu kullanılarak hesaplanmıştır.

Şekil 2'de Alpaslan mahalelsinde bulunan bina verileri ve dini tesis verileri sunulmuştur. Şekil 2'de görüldüğü üzere Alpaslan mahallesinde 3 adet dini tesis bulunmaktadır. Şekil 2'de bulunan dini tesisler diktörtgen ile belirtilmiştir. Ayrıca bu veri kümesinde toplamda 236 adet bina verisi bulunmaktadır.
Nokta üzerinde bulunmayan $\mathrm{X}$ işareti ise algoritmanın önerdiği dini tesis konumunu ifade etmektedir. 


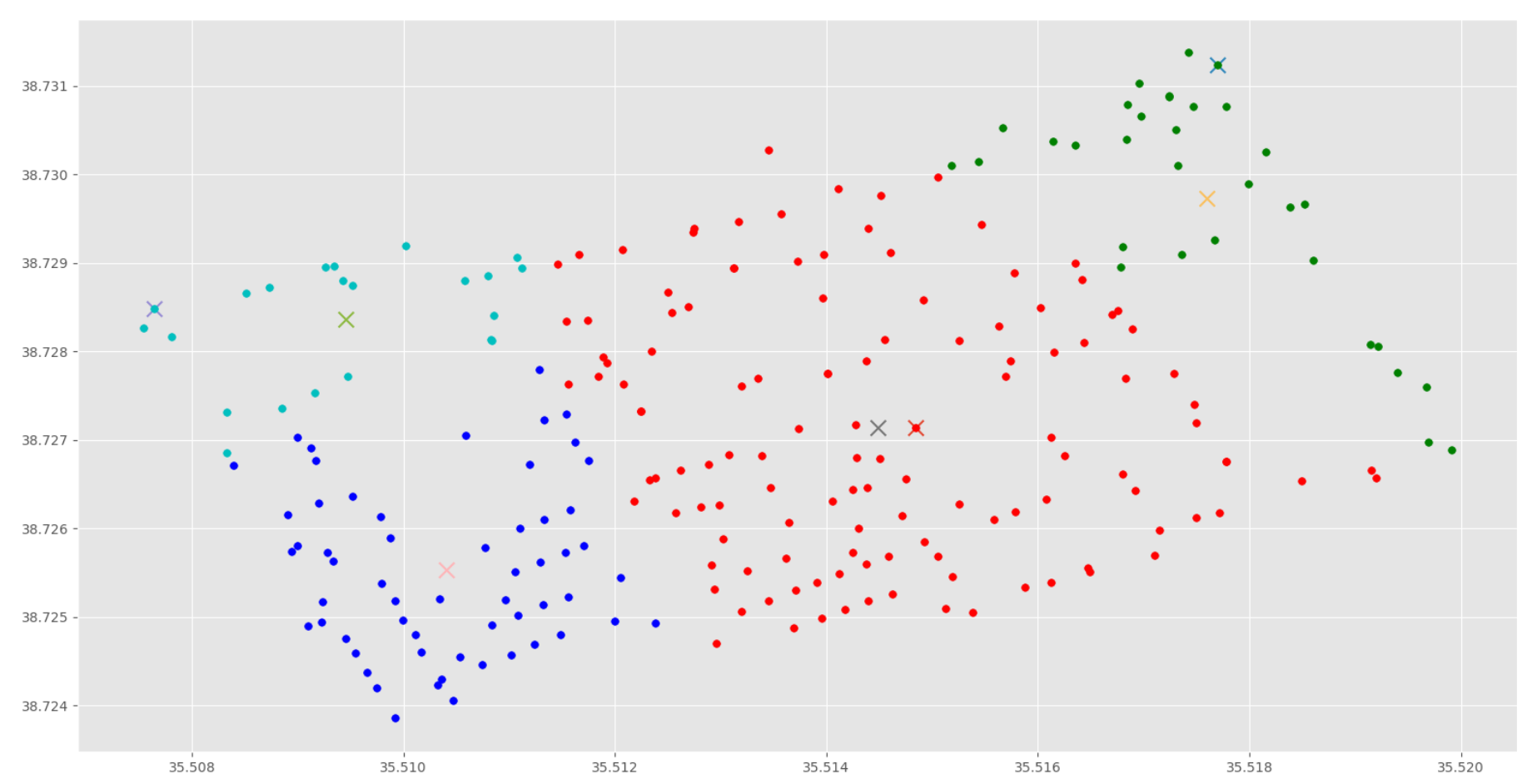

Şekil 3 İki Boyutlu K-means Yönteminin Oluşturduğu Kümeler

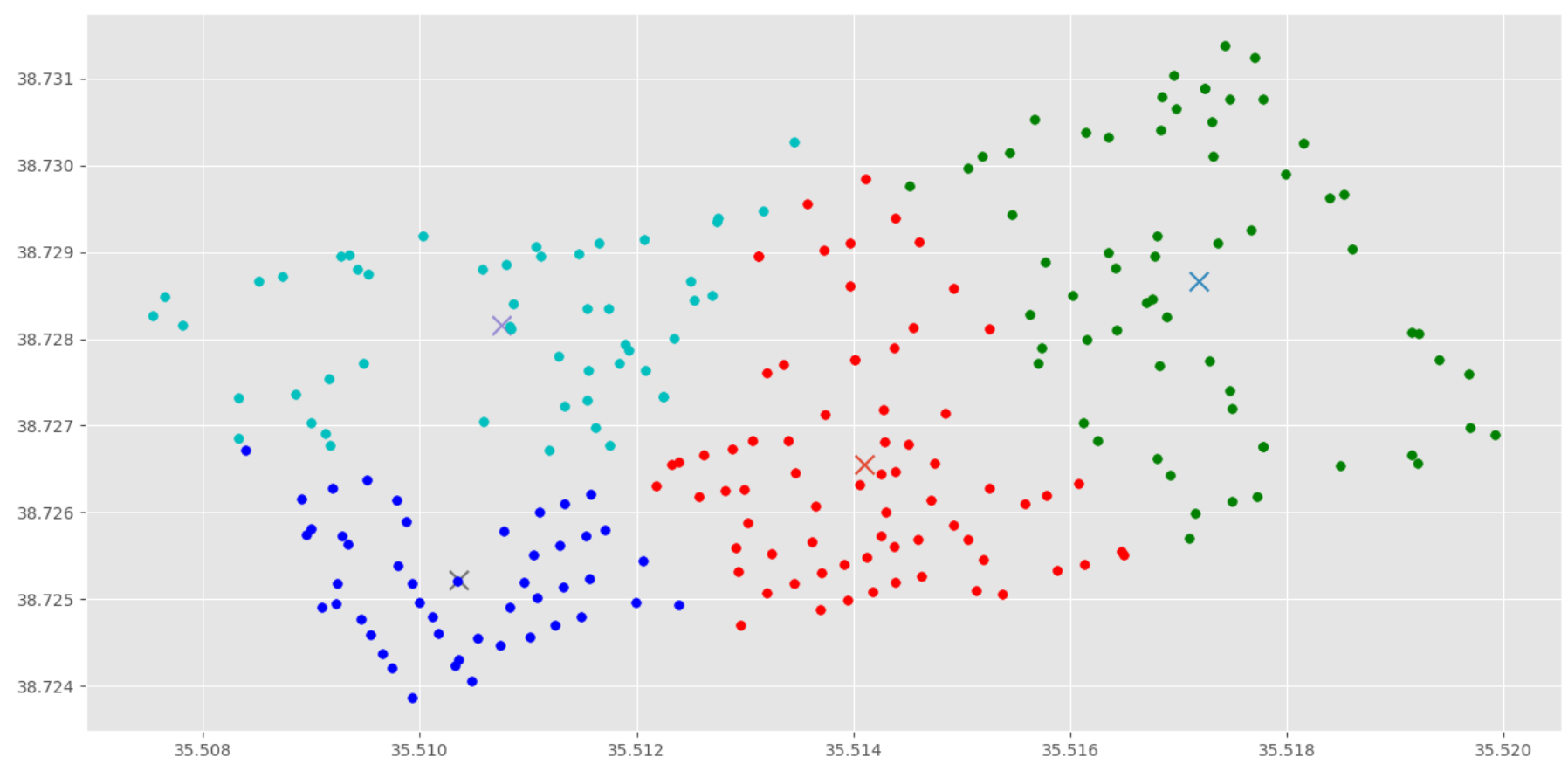

Şekil 4 Çok Boyutlu K-means Yönteminin Oluşturduğu Kümeler

Yöntemlerin başarım performansı ise Şekil 5'te sunulmuştur. $\mathrm{Bu}$ çalışma kapsamında kullanılan veri kümesinde toplam 2065 adet bağımsız bölüm bulunmaktadır. Bağımsız bölüm sayısı dört kümeye yani dört adet dini tesise eşit olarak bölündüğünde bir dini tesis için yaklaşık olarak 518 adet bağımsız bölüm düşmektedir. Yöntemlerin oluşturmuş olduğu kümede bulunan bağımsız bölüm sayısı ortalama bağımsız bölüm sayısına ne kadar yakın ise yöntemler o kadar başarılıdır. Şekil 5'te görüldüğü üzere önerilen çok boyutlu k-means yöntemi iki boyutlu k-means yöntemine göre birinci, ikinci ve üçüncü küme için çok üstün performans göstermiştir. Dördüncü kümede ise iki boyutlu kmeans algoritması çok boyutlu k-means algoritmasına göre daha başarılı gibi gözükse de çok boyutlu k-means algoritması mesafeleri de dikkate aldığından ve dördüncü kümede binalar arasındaki mesafe çok olduğundan dolayı aslında çok boyutlu kmeans algoritması bu kümede de başarılı sonuç üretmiştir. 


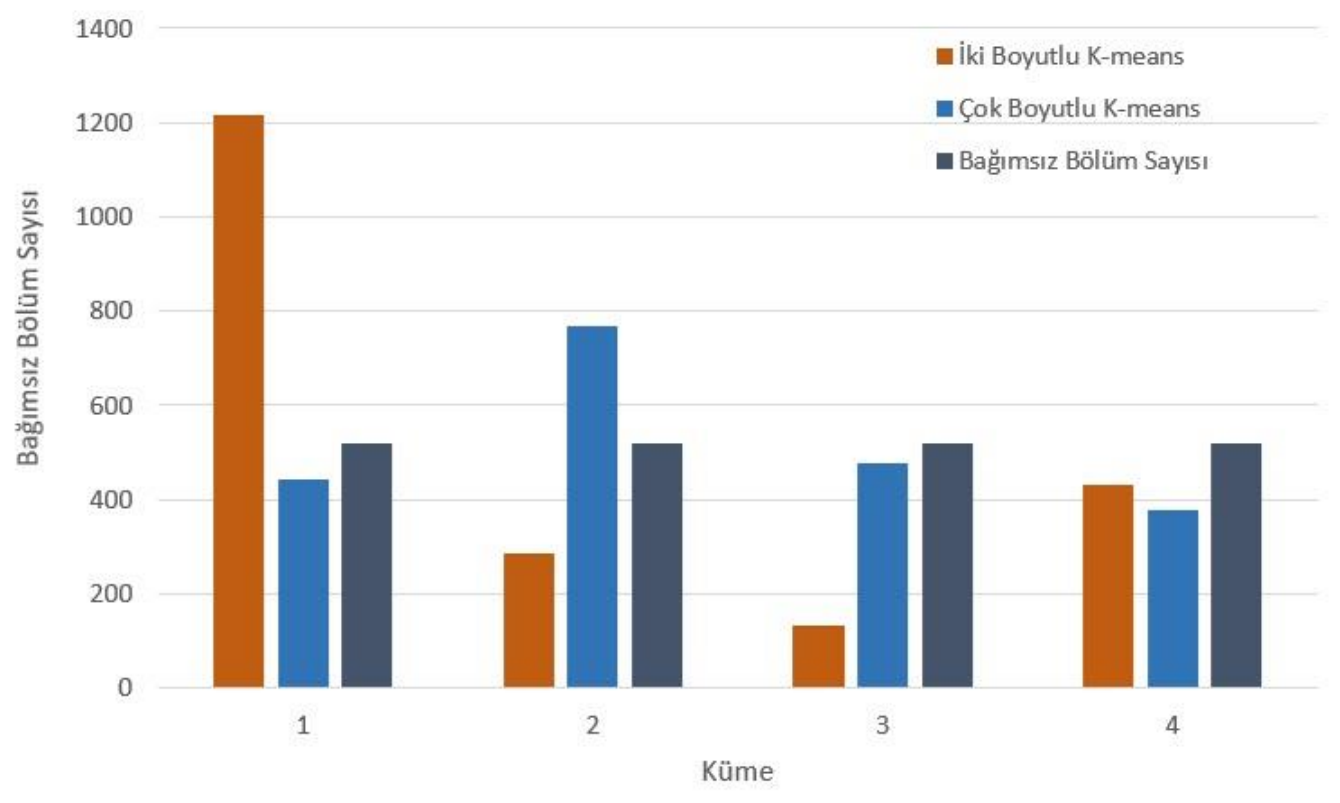

Şekil 5 Yöntemlerin Başarım Performansı

\section{Sonuç}

Dini tesis konumları, insanlar tarafından ilgi çekici bulunan ve etkileşim kurulmak istenen önemli bir POI öğeisidir. Bu nedeniyle dini tesis yapılacak konum daha önemli hale gelmiştir. K-means algoritması yoğunluk tabanlı olarak çalışan, küme sayısı önceden bilinmesi gereken, bütün öğeleri kümeye dahil eden bir algoritma olduğundan dolayı dini tesis konumu tespitine uygun bir yöntemdir. Bu çalışmada iki boyutlu ve çok boyutlu k-means yöntemi ile yeni yapılacak dini tesis konumu için en uygun yer tespit edilmeye çalışılmış ve nüfüs yoğunluğuna göre başarım değerlendirildiğinde çok boyutlu k-means algoritması daha başarılı sonuçlar elde etmiştir.

\section{Teşekkür}

Melikgazi Belediyesi ilçe sınırları içerisinde bulunan bina konum verilerini ve dini tesis konum verilerini paylaştı̆̆ 1 için Melikgazi Belediyesi ve Kayseri Büyükşehir Belediyesi’ne teşekkür ederiz.

\section{Kaynakça}

Anderson, T. K. (2009). Kernel density estimation and K-means clustering to profile road accident hotspots. Accident Analysis \& Prevention, 41(3), 359-364.

Askarovich, A. B. (2021). Cluster methods for the development of thinking of students of informatics. Academy, (3 (66)), 1314.

Brimicombe, A. J. (2007). A dual approach to cluster discovery in point event data sets. Computers, environment and urban systems, 31(1), 4-18.
Caron, M., Misra, I., Mairal, J., Goyal, P., Bojanowski, P., \& Joulin, A. (2020). Unsupervised learning of visual features by contrasting cluster assignments. arXiv preprint arXiv:2006.09882.

Çolak, B., Durdağ, Z., \& Edoğmuş, P. (2016). K-Means Algoritması İle Otomatik Kümeleme. El-Cezeri Fen ve Mühendislik Dergisi, 3(2).

Danielsson, P. E. (1980). Euclidean distance mapping. Computer Graphics and image processing, 14(3), 227-248.

Deng, Z., Chen, Y., Pan, X., Peng, Z., \& Yang, J. (2021). Integrating GIS-based Point of Interest and Community Boundary Datasets for Urban Building Energy Modeling. Energies, 14(4), 1049.

El Khediri, S., Fakhet, W., Moulahi, T., Khan, R., Thaljaoui, A., \& Kachouri, A. (2020). Improved node localization using Kmeans clustering for Wireless Sensor Networks. Computer Science Review, 37, 100284.

Hamerly, G., \& Elkan, C. (2003). Learning the k in k-means. Advances in neural information processing systems, 16, 281288.

Han, J., Lee, J. G., \& Kamber, M. (2009). An overview of clustering methods in geographic data analysis. Geographic data mining and knowledge discovery, 2, 149-170.

Hashim, R., Ikhmatiar, M. S., Surip, M., Karmin, M., \& Herawan, T. (2011). Mosque tracking on mobile GPS and prayer times synchronization for unfamiliar area. International Journal of Future Generation Communication and Networking, 4(2), $37-48$.

Ke, C. K., Wu, M. Y., Ho, W. C., Lai, S. C., \& Huang, L. T. (2018). Intelligent Point-of-Interest Recommendation for Tourism Planning via Density-based Clustering and Genetic Algorithm. In PACIS (p. 140). 
Kodinariya, T. M., \& Makwana, P. R. (2013). Review on determining number of Cluster in K-Means Clustering. International Journal, 1(6), 90-95.

Kozinska, D., Tretiak, J., Nissanov, J., \& Ozturk, C. (1997). Multidimensional alignment using the Euclidean distance transform. Graphical models and image processing, 59(6), 373-387.

Krause, C. M., \& Zhang, L. (2019). Short-term travel behavior prediction with GPS, land use, and point of interest data. Transportation Research Part B: Methodological, 123, 349-361.

Kuswandi, D., Surahman, E., Thaariq, Z. Z. A., \& Muthmainnah, M. (2018, October). K-Means clustering of student perceptions on project-based learning model application. In 2018 4th International Conference on Education and Technology (ICET) (pp. 9-12). IEEE.

Likas, A., Vlassis, N., \& Verbeek, J. J. (2003). The global k-means clustering algorithm. Pattern recognition, 36(2), 451-461.

Long, Y., Song, Y., \& Chen, L. (2021). Identifying subcenters with a nonparametric method and ubiquitous point-of-interest data: A case study of 284 Chinese cities. Environment and Planning B: Urban Analytics and City Science, 2399808321996705.

Na, S., Xumin, L., \& Yong, G. (2010, April). Research on k-means clustering algorithm: An improved k-means clustering algorithm. In 2010 Third International Symposium on intelligent information technology and security informatics (pp. 63-67). Ieee.

Sariman, G. (2011). Veri madenciliğinde kümeleme teknikleri üzerine bir çalışma: k-means ve k-medoids kümeleme algoritmalarının karşılaştırılması. Süleyman Demirel Üniversitesi Fen Bilimleri Enstitüsü Dergisi, 15(3), 192-202.

Selvi, H. Z., \& Çağlar, B. (2017). Çok Değişkenli Haritalama İçin Kümeleme Yöntemlerinin Kullanilmasi. Niğde Ömer Halisdemir Üniversitesi Mühendislik Bilimleri Dergisi, 6(2), 415-429.

Shouman, M., Turner, T., \& Stocker, R. (2012). Integrating decision tree and k-means clustering with different initial centroid selection methods in the diagnosis of heart disease patients. In Proceedings of the International Conference on Data Science (ICDATA) (p. 1). The Steering Committee of The World Congress in Computer Science, Computer Engineering and Applied Computing (WorldComp).

Taşyürek, M. (2021). Mekân-Zamansal Veri Madenciliği Yöntemi ile Otobüs Durak İhlallerinin Tespiti. Avrupa Bilim ve Teknoloji Dergisi, (24), 449-454.

Taşyürek, M., \& Çelik, M. (2021). FastGTWR: Hızlı coğrafi ve zamansal ağırlıklı regresyon yaklaşımı. Gazi Üniversitesi Mühendislik Mimarlık Fakültesi Dergisi, 36(2), 715-726.

Wang, H., Shen, H., Ouyang, W., \& Cheng, X. (2018, July). Exploiting POI-Specific Geographical Influence for Point-ofInterest Recommendation. In IJCAI (pp. 3877-3883).

Yu, L., Yu, T., Wu, Y., \& Wu, G. (2020). Rethinking the identification of urban centers from the perspective of function distribution: A framework based on point-of-interest data. Sustainability, 12(4), 1543.
Zeng, Q. T., Pratt, J. P., Pak, J., Ravnic, D., Huss, H., \& Mentzer, S. J. (2007). Feature-guided clustering of multi-dimensional flow cytometry datasets. Journal of Biomedical Informatics, 40(3), 325-331. 